\title{
Erratum to: Efficiency of the modal shift and environmental policy on the Korean railroad
}

\author{
Jung-Wouk Woo $\cdot$ Chang-Yeoul Choi $\cdot$ \\ Hyoung-Gi Kim • Yongrok Choi • \\ Kyonghwan Kim $\cdot$ Desheng Dash Wu
}

Published online: 13 April 2010

(C) Springer-Verlag 2010

\section{Erratum to: Stoch Environ Res Risk Assess \\ DOI 10.1007/s00477-010-0369-0}

The order of authors in the paper Efficiency of the modal shift and environmental policy on the Korean railroad, DOI 10.1007/s00477-010-0369-0, was incorrectly listed.

The online version of the original article can be found under doi:10.1007/s00477-010-0369-0.

\section{J.-W. Woo}

Korea National Railroad College for Railroad Transportation Department, Uiwang, South Korea

e-mail: jungwouk@hanmail.net

\section{C.-Y. Choi · H.-G. Kim}

Jungseok Research Institute of International Logistics and Trade, Incheon, South Korea

e-mail: ccy666@inha.ac.kr

H.-G. Kim

e-mail: khk601@inha.ac.kr

\section{Y. Choi}

Department of International Trade, Inha University, Incheon 402-751, South Korea

e-mail: yrchoi@inha.ac.kr
The correct order is listed above and should be regarded by the reader as the final version. 